\title{
Laboratory diagnosis of the Niemann-Pick type C disease: an inherited neurodegenerative disorder of cholesterol metabolism
}

\author{
Dominika Sitarska $^{1} \cdot$ Agnieszka Ługowska $^{1}$ (])
}

Received: 21 February 2019 / Accepted: 28 May 2019 / Published online: 13 June 2019

(C) The Author(s) 2019

\begin{abstract}
Niemann-Pick type C disease (NPC) is a genetically determined neurodegenerative metabolic disease resulting from the mutations in the $N P C 1$ or $N P C 2$ genes. It belongs to the lysosomal storage diseases and its main cause is impaired cholesterol transport in late endosomes or lysosomes. NPC is inherited in an autosomal recessive trait. Due to the wide range in age of onset, often unspecific clinical picture and varying dynamics of disease progression, the diagnosis is very difficult and long-lasting. The most characteristic visceral symptoms are hepato- or hepatosplenomegaly, which may appear independently of neurological or psychiatric symptoms at various stages of the disease. Available biochemical biomarkers should be tested as early as possible in patients presenting with hepato- or hepatosplenomegaly, long-lasting cholestatic jaundice in neonates or infantile patients, as well as in individuals at any age with: vertical supranuclear gaze palsy (VSGP), ataxia, dystonia, frontotemporal dementia and untreatable schizophrenia or psychosis. Research on biomarkers which can detect NPC patients (Cholestan-3 $\beta, 5 \alpha, 6 \beta$-triol, 7-ketocholesterol, lysosphingomyelin isoforms and bile acid metabolites) is still ongoing, although they are not specific for the NPC disease only. This mini review describes currently used diagnostic methods.
\end{abstract}

Keywords Niemann-Pick type $\mathrm{C}$ disease $\cdot$ Oxysterols $\cdot$ Chitotriosidase $\cdot$ Bile acid metabolites $\cdot$ Lysosphingolipids $\cdot$ Filipin staining test

\section{Introduction}

Niemann-Pick type C disease (NPC; OMIM \#257220 and OMIM \#607625) is a genetic, neurodegenerative disease classified to the group of lysosomal storage diseases, caused by the accumulation of free cholesterol and secondarily other complex lipid compounds in lysosomes or late endosomes.

This disease is caused by pathogenic mutations in NPC1 (OMIM \#607623) and NPC2 (OMIM \# 601015) genes. The NPC1 gene encodes a large, transmembrane $142 \mathrm{kDa}$ protein located in the lysosomal membrane (Bauer et al. 2002). The $N P C 2$ gene encodes a small $(\mathrm{MW}=16 \mathrm{kDa})$, soluble protein with high affinity to cholesterol, located inside late endosomes or lysosomes (Ko et al. 2003). Mutations in these genes lead to disturbances in the intracellular cholesterol transport, which

Agnieszka Ługowska

alugipin@yahoo.com

1 Department of Genetics, Institute of Psychiatry and Neurology, Al. Sobieskiego 9, 02-957 Warsaw, Poland result in the sequestration of unesterified cholesterol and secondarily some other sphingolipids inside the lysosomes or late endosomes. In normal metabolic cycle free cholesterol liberated from lysosomes is transported to the Golgi apparatus and then esterified in the endoplasmic reticulum by Acyl-CoA cholesterol acyltransferase (ACAT) (Erickson 2013).

NPC is a rare, inherited in an autosomal recessive trait disease, whose prevalence is 1.12: 100,000 of live births for classical forms, but due to diagnostic difficulties this number is probably higher (Wassif et al. 2016).

The spectrum of the clinical picture of NPC is extremely heterogeneous. The age of onset of symptoms may vary from perinatal period to adulthood. Similarly, patients' lifespan can range from a few days to even 60 years, but most patients die between 10 and 25 years of age (Wraith et al. 2009; Spiegel et al. 2009).

The most characteristic visceral symptoms are hepato- or hepatosplenomegaly, which may appear independently of neurological or psychiatric symptoms at various stages of the disease. Except of the small group of patients, who die at birth or in the first months of life due to liver or respiratory failures, all patients will eventually develop progressive and 
fatal neurological disease. Visceral symptoms, if present usually precede neurological symptoms and occur in about $85 \%$ of patients.

The most characteristic neurological symptoms are cerebellar ataxia, dysarthria, dysphagia and developmental delay or progressive dementia. The majority of patients show a characteristic vertical supranuclear gaze palsy (VSGP) (Solomon et al. 2005). Cataplexy, epileptic seizures and dystonia are also common and psychiatric symptoms, present in patients with late onset of the disease include e.g. psychosis, paranoid delusions or schizophrenia. Depending on the patient's age at the time of the first neurological symptoms and the dynamics of disease progression several types of the disease are distinguished (Table 1) (Patterson et al. 2001; Vanier and Millat 2003; Wraith et al. 2009; Vanier 2010).

Early infantile type refers to patients, in whom first clinical symptoms occur between 2 months and 2 years of life. In this form of NPC hepatosplenomegaly is always present. Additionally, neurological symptoms such as psychomotor delay are observed at about 8-9 months of age and also hypotonia, which may appear between 1 and 2 years of age. Survival rarely exceeds 5 years.

In the late-infantile type of NPC first symptoms such as hepatosplenomegaly, speech delay, and walking problems caused by ataxia are observed in children between 2 and 6 years of age. VSGP, cataplexy, and epileptic seizures are common. The mental retardation progresses, dysphagia, dysarthria and dementia develop. In the later stages of the disease, pyramidal symptoms appear and spasticity and swallowing problems occur. These patients most often die between 7 and 12 years of age.

In the juvenile type of NPC the first neurological symptoms appear most often between 6 and 15 years of age and they include VSGP, difficulties in writing, disordered attention, cataplexy usually caused by laughter. Dysarthria, dysphagia, functional dystonia, severe motor delay and intellectual decline are developing. Similarly to the NPC types of earlier onset pyramidal symptoms, spasticity and swallowing problems requiring gastrostomy may appear (Vanier 2010).
In the adult type, psychiatric symptoms such as psychosis, paranoid delusions, visual and auditory hallucinations, depressive syndromes, sometimes bipolar disorder, obsessivecompulsive disorder or schizophrenia are characteristic (Kawazoe et al. 2018). The neurological symptoms may include cerebellar ataxia, dysarthria, cognitive disorders, movement disorders, and dysphagia (Sevin et al. 2007). It should be emphasized that in this type of NPC the neurological symptoms may not occur or they can be very subtle.

Although there is no a cure for NPC, the clinical symptoms of this inborn metabolic disorder can be still treated. A cooperation of a multi-disciplinary team of specialists, including neurologist, metabolist, psychiatrist, ophthalmologist, gastroenterologist, psychologist and others, brings benefits for patient's health if introduced at an early stage of manifestations. Neurological symptoms can be attenuated by means of substrate reduction therapy (SRT) with miglustat, which is an imino sugar inhibiting the activity of glucosylceramide synthase, an enzyme involved in the biosynthesis of most glycosphingolipids. So far, this is the only approved therapy for NPC (Geberhiwot et al. 2018). Clinical trials are performed for experimental treatment with 2-hydroxypropyl- $\beta$-cyclodextrin, an activator of heat shock response (Arimoclomol) and acetyl-DL-leucine (Walterfang et al. 2012; Patterson et al. 2007, 2012; Ory et al. 2017; Bremova et al. 2015). Studies in NPC animal models demonstrated that early treatment may reduce the progress of neurological symptoms (Zervas et al. 2001).

\section{Laboratory diagnosis}

Due to unspecific clinical signs and symptoms observed in patients affected with NPC the diagnostic process is difficult and long-lasting. Lack of one specific method giving a clear result confirming or excluding the disease demands the combination of biochemical and molecular techniques.

Available biochemical biomarkers should be tested as early as possible in patients presenting with hepato- or hepatosplenomegaly, long-lasting cholestatic jaundice in neonates or infants as well as in patients at any age with:

Table 1 Main clinical manifestations observed in different types of NPC (partly on the basis of Vanier 2010)

\begin{tabular}{|c|c|c|c|c|}
\hline Type NPC & Early infantile & Late infantile & Juvenile & Adult \\
\hline Systemic involvement & $\begin{array}{l}\text { Hepatosplenomegaly } \\
\text { May regress with age } \\
\text { Absent in } \sim 15 \% \text { of cases }\end{array}$ & & & \\
\hline Neurological involvement & $\begin{array}{l}\text { - Delay in motor milestones } \\
\text { - Hypotonia } \\
\text { - VSGP }\end{array}$ & $\begin{array}{l}\text { - Gait problems } \\
\text { - Clumsiness } \\
\text { - Speech delay } \\
\text { - Cataplexy } \\
\text { - VSGP }\end{array}$ & $\begin{array}{l}\text { - School problems } \\
\text { - Ataxia } \\
\text { - Seizures } \\
\text { - Cataplexy } \\
\text { - VSGP }\end{array}$ & $\begin{array}{l}\text { - Psychiatric problems } \\
\text { - Ataxia } \\
\text { - Dystonia } \\
\text { - Dementia } \\
\text { - VSGP }\end{array}$ \\
\hline
\end{tabular}


VSGP, ataxia, dystonia, frontotemporal dementia and untreatable schizophrenia or psychosis (Patterson et al. 2017). It is also worth to remember that there is a strong suspicion of NPC in patients with unclarified hematologic problems (especially, when sea blue histiocytes are present in the bone marrow aspirates).

In this section we will shortly describe the main laboratory methods available in diagnostics of NPC (both biochemical and molecular). The filipin staining test was the first one, which has been used for identification of NPC individuals for over 30 years (Pentchev et al. 1985). Since filipin test is invasive, long lasting and laborious there was an expectation on fast and easy tests in blood. In 1994, Hollak et al. revealed chitotriosidase to be a novel biomarker for Gaucher disease but it soon was demonstrated that moderate elevation of chitotriosidase activity can be found in patients with some other lysosomal diseases and among them also in NPC (Hollak et al. 1994; Ries et al. 2006). Due to the limitation that chitotriosidase activity can remain in reference ranges, especially in NPC patients affected with late onset forms of the disorder, some novel techniques have been developed recently for biomarkers including oxysterols, lysosphingolipids, bile acid metabolites, and Bis(monoacylglycero)phosphate (BMP/LBPA). Since early 1990, molecular analyses based on polymerase chain reaction method (PCR) are available in the diagnostic process of NPC. They are particularly useful when results of biochemical biomarkers are difficult for interpretation or the filipin test is inconclusive.

\section{Biochemical biomarkers}

\section{Filipin staining test}

Staining with filipin, a fluorescent chemical compound isolated from actinomycete, Streptomyces filipinensis, until recently was considered the gold standard in NPC diagnostics. This method is invasive because of using the skin fibroblasts taken of patients. Initially, fibroblasts are cultured in a medium deprived of cholesterol compounds to maximize the LDL receptor's response, and then the cells are incubated for $24 \mathrm{~h}$ in LDL-enriched medium. Prior to staining with filipin, cells must be fixed with $10 \%$ buffered formalin (Vanier et al. 2016).

In fluorescence microscope, cultured NPC skin fibroblasts usually show an increased number of perinuclear luminescent vesicles, see Fig. 1. About $80-85 \%$ of cases show this 'classical' pattern of staining (Vanier et al. 2016). The remaining cases are referred to as the 'variant' biochemical phenotype, where the intensity of filipin staining is not as clear. This situation can be observed in the case of several specific mutations, e.g. p.Pro1007Ala, in some NPC heterozygotes as well as in patients with Niemann-Pick type A or B diseases (acid sphingomyelinase deficiency), lysosomal acid lipase deficiency and mucolipidosis II/III (I-cell disease) (Vanier et al. 1991).

Abnormal results of filipin staining test have also been documented in MEGDEL syndrome, Smith-Lemli-Opitz syndrome, Tangier disease, and in a rare congenital disorder of glycosylation due to Nogo-B receptor mutations (Vanier et al. 2016). Vanier et al. indicated additionally that in mouse cells deficient in mannose- 6-phosphate receptors, MPR46 and MPR300, altered filipin staining patterns have been shown (Vanier et al. 2016).

For a completed diagnosis, filipin staining should always be combined with the detection of pathogenic molecular failures in the NPC1 and NPC2 genes.

\section{Chitotriosidase}

Plasma/serum chitotriosidase activity test is most often performed for the detection of patients with Gaucher disease, in whom the elevation is significant. A moderate increase in

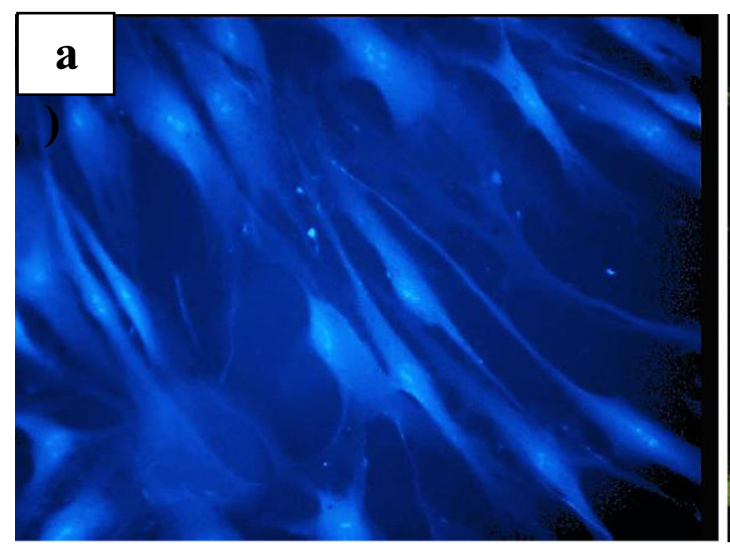

Fig. 1 Example of filipin staining of cultured skin fibroblasts in diagnosing NPC. Cells taken from a healthy control person and patient affected with NPC were initially cultured in standard medium followed by lipoprotein deprivation for a few days and then a renewed addition of



lipoprotein source to the medium. a Picture of control cells. b Multiple fluorescent granules are visible in perinuclear space (seen in fluorescent microscope). The picture shows 'classical' storage pattern of results seen in NPC 
chitotriosidase activity is also observed in individuals with NPA, NPB, NPC, lysosomal acid lipase deficiency (Wolman disease, CESD), gangliosidosis GM1, and Krabbe disease (Ries et al. 2006; Wajner et al. 2007). However, chitotriosidase activity may not always be increased in NPC patients, especially in those with late onset types of the disease. The increased activity of this enzyme is also possible in other disorders such as type II diabetes or stroke (Elmonem et al. 2016; Sotgiu et al. 2005; Bustamante et al. 2014). Noteworthy, about $10 \%$ of general population are homozygotes for chitotriosidase deficiency alleles leading to uninformative results (Ries et al. 2006).

\section{Oxysterols}

Oxidative stress leads to the non-enzymatic formation of cholesterol self-oxidising products and to the increased production of reactive oxygen species (ROS). In patients with NPC disease elevated levels of cholestane- $3 \beta, 5 \alpha, 6 \beta$-triol (C-triol) and 7-ketocholesterol (7-KC) in plasma were demonstrated (Porter et al. 2010; Jiang et al. 2011). This discovery allowed for faster diagnostics of the disease. Tests for the detection of oxysterols use gas chromatography - mass spectrometry (GCMS) (Porter et al. 2010) or liquid chromatography - tandem mass spectrometry (LC-MS/MS) methods (Jiang et al. 2011).

However, it has been reported that in several cases of NPC patients no significant increase in the level of oxysterols or their borderline values were observed (Stampfer et al. 2013; Jiang et al. 2011; Reunert et al. 2016; Amraoui et al. 2014). Additionally, in frequent patients it is almost impossible to discriminate NPC from NPA/B individuals on the basis of only Ctriol and 7-KC levels (Klinke et al. 2015; Romanello et al. 2016; Reunert et al. 2016; Pagan et al. 2015; Amraoui et al. 2014; Lin et al. 2014). The increased levels of oxysterols were also described in patients with lysosomal acid lipase deficiency (Pajares et al. 2015; Reunert et al. 2016; Pagan et al. 2015; Amraoui et al. 2014; Boenzi et al. 2014). Jiang and Romanello reported a small but significant increase in C-triol and 7-KC levels in carriers of mutation in the $\mathrm{NPCl}$ gene (in $25 \%$ and $36 \%$, respectively) (Jiang et al. 2011; Romanello et al. 2016).

Due to their non-invasive character, low costs and short time of analysis, oxysterol tests can be used in screening for NPC. These tests are performed in small samples of serum or EDTA-plasma but it should be kept in mind, that this method requires a rigorous preanalytical procedure (Helmschrodt et al. 2014). Otherwise, false positive results are possible (especially in the case of 7-KC) due to the hemolysis or improper storage or transport of samples.

In addition to C-triol and 7-KC other oxysterols may be increased in the blood of NPC patients or animal models including: $7 \beta$-hydroxycholesterol ( $7 \beta$-HC), $4 \beta$-hydroxycholesterol $(4 \beta-\mathrm{HC}), 7 \alpha$-hydroxycholesterol $(7 \alpha-\mathrm{HC})$ and 25 hydroxycholesterol (25-HC). In a mouse model NPC, a subset of cholesterol oxidation products (25-HC, $3 \beta, 5 \alpha, 6 \beta$-triol, 7$\mathrm{KC}, 7 \alpha-\mathrm{HC}$ and $7 \beta-\mathrm{HC}$ ) were all increased in the plasma of the 4 week old animals. Interestingly, in plasma samples from NPC1 patients the level of 24(S)-hydroxycholesterol (24(S)HC) was lower than in controls (Porter et al. 2010; Ribas et al. 2016; Hammerschmidt et al. 2018).

\section{Lysosphingolipids}

In NPC, besides cholesterol, other lipids such as sphingolipids can be stored secondarily. Among them gangliosides are most abundant. Sphingolipids are essential components of plasma membranes in eukaryotic cells, especially in the nervous system, and they are important bioactive molecules (MalagarieCazenave et al. 2002). Genetic defects of enzymes or other proteins needed for their degradation lead to a subgroup of lysosomal storage diseases (LSD) called sphingolipidoses (Kolter and Sandhoff 2006).

According to their chemical structure, lysosphingolipids are deacylated derivatives of the starting sphingolipids. They are considered to be cytotoxic metabolites that contribute to the pathophysiology of LSD.

In patients with NPC, a slight increase of lysosphingomyelin (LysoSM) was demonstrated (Welford et al. 2014), and a much higher increase of its carboxylated analogue (LysoSM509) (Giese et al. 2015). Their levels can be examined with the use of LC-MS/MS technique. Research of Petazzoni et al. confirmed the elevation of LysoSM and LysoSM509 in the plasma of patients with NPA and NPB, and the increase of LysoSM509 without significant increase of LysoSM in patients with NPC (Pettazzoni et al. 2017). Similar results were obtained in earlier studies on these two biomarkers (Chuang et al. 2014; Welford et al. 2014; Giese et al. 2015; Polo et al. 2016; Raymond et al. 2015). Simultaneous examination of both biomarkers allows distinguishing NPA or B from NPC patients (Polo et al. 2016; Vanier et al. 2016). However, there were few cases of NPB patients described, in whom LysoSM in plasma was normal (Kuchar et al. 2017) and elevated levels of LysoSM and LysoSM509 were observed in several patients with Gaucher disease (Polo et al. 2016; Ferraz et al. 2016). Analysis of lysosphingolipids levels in plasma can be used for a screening or differential diagnosis in newborns with hepatosplenomegaly (Pettazzoni et al. 2017).

On the basis of LysoHexCer, LysoSM and LysoSM509 levels the discrimination of NPA/B, NPC, Gaucher disease, and Krabbe disease patients is possible (Pettazzoni et al. 2017; Polo et al. 2016) (please, see the Table 2).

In patients with NPC and in other lysosomal storage disorders, a pathological increase in Bis(monoacylglycero)phosphate (BMP or LBPA - lysobisphosphatidic acid) was described. BMP is a structural isomer of phosphatidylglycerol, localized in the internal membranes of late endosomes where it forms specialized lipid domains. BMP is taking part especially in the control 
Table 2 Diagnostic techniques used in recognizing NPC, overview (partly on the basis of Vanier et al. 2016)

\begin{tabular}{|c|c|c|c|c|}
\hline Technique & Method & Material & Duration & Limitations \\
\hline Genetic testing & $\begin{array}{l}\text { Sanger Sequencing, } \\
\text { NGS, MLPA }\end{array}$ & $\begin{array}{l}\text { Low invasive - small } \\
\text { samples of EDTA blood }\end{array}$ & Long analysis & $\begin{array}{l}\text { Used as confirmatory diagnostic } \\
\text { test because of high cost and } \\
\text { very long analysis }\end{array}$ \\
\hline Plasma oxysterol testing & LC-MS/MS or GC-MS & $\begin{array}{l}\text { Low invasive - small } \\
\text { samples of plasma } \\
\text { (EDTA) }\end{array}$ & Rapid analysis & $\begin{array}{l}\text { May be elevated in other } \\
\text { diseases, possible false } \\
\text { positive results due to } \\
\text { incorrect transport or storage } \\
\text { of samples }\end{array}$ \\
\hline Lysosphingolipids testing & LC-MS/MS & $\begin{array}{l}\text { Low invasive - small } \\
\text { volume of blood }\end{array}$ & Rapid analysis & $\begin{array}{l}\text { LysoSM509 does not } \\
\text { distinguish NPC from Acid } \\
\text { Sphingomyelinase } \\
\text { Deficiency patients }\end{array}$ \\
\hline $\begin{array}{l}\text { Bile acids } \\
\text { metabolites testing }\end{array}$ & LC-MS/MS & $\begin{array}{l}\text { Very low invasive - } \\
\text { urine, dried blood } \\
\text { spots, plasma }\end{array}$ & Rapid analysis & $\begin{array}{l}\text { May be elevated in Acid } \\
\text { Sphingomyelinase } \\
\text { Deficiency }\end{array}$ \\
\hline Filipin staining & $\begin{array}{l}\text { Cell culture, cytochemistry, } \\
\text { fluorescence microscopy } \\
\text { evaluation }\end{array}$ & Invasive skin biopsy & Long analysis & $\begin{array}{l}\text { High cost, rigorous conditions } \\
\text { and expertise in interpretation } \\
\text { are critical. } \\
\text { Some other diseases may } \\
\text { produce positive results. }\end{array}$ \\
\hline
\end{tabular}

of cellular cholesterol distribution. Research of Liu and coworkers showed a 50-fold increase of di-22:6-BMP in the urine of NPC patients (Liu et al. 2014). However clinical utility of BMP in NPC diagnostics is still unknown.

\section{Bile acids metabolites}

Impaired cholesterol transport in patients with NPC, may result in utilization of several bile acid synthesis pathways different from these active in healthy people. In patients, a unique set of bile acids excreted in the urine has been identified. They include unsaturated $\mathrm{C} 24$ bile acids (5-cholenoic acids) with a sulfated $3 \beta$-hydroxyl group, a $7 \beta$-hydroxyl group, either free or conjugated with $\mathrm{N}$-acetylglucosamine (GlcNAc) and the C24 carboxyl group either free or conjugated with glycine or taurine (Alvelius et al. 2001). It has been hypothesized that bile acids profile unique to NPC patients can be produced as a result of hepatic metabolism of 7-oxo-cholesterol, presumably by $3 \beta, 7 \beta$-dihydroxy-5-cholenic acid and its $7 \beta-\mathrm{N}$ acetylglucosamine conjugate. The results published by Maekawa showed a 400-fold increase in urinary excretion of $3 \beta$-sulfoxy-7 $\beta$-N-acetyl-glucosamine-5-cholenic acid (SNAG-CA) and its conjugates with glycine (SNAG-G) and taurine (SNAG-T) (Maekawa et al. 2013). Recent studies revealed the presence of another bile acid, namely $3 \beta, 5 \alpha, 6 \beta$ trihydroxycholanic acid and its conjugates with glycine and taurine. Jiang et al. showed that cholestane- $3 \beta, 5 \alpha, 6 \beta$-triol is a precursor for $3 \beta, 5 \alpha, 6 \beta$-trihydroxycholanic acid, and then its transformation results in a more polar conjugate with gly-

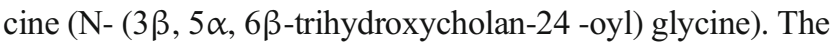

increase in the content of these acids in the plasma was 41-fold and 144-fold (respectively), which allows distinguishing NPC patients from control individuals. Another bile acid has been also identified, probably a $3 \beta, 5 \alpha, 6 \beta$-trihydroxycholanic acid conjugate with taurine, but the increase in concentration in patients compared to control was only 6-fold higher, and in some cases its level coincided with that in healthy people (partial overlap with controls). Therefore, further research on it was discontinued (Jiang et al. 2016).

Subsequent studies on the content of $3 \beta, 5 \alpha, 6 \beta$ trihydroxycholanic acid and $\mathrm{N}-(3 \beta, 5 \alpha, 6 \beta-$ trihydroxycholan-24-oyl) glycine in plasma in newborns and children over 1 year of age showed that the first one was present in all NPC newborn infants, while in older NPC children some results overlapped with controls. For the second of the bile acids the situation was reversed (Jiang et al. 2019). It can therefore be concluded that $3 \beta, 5 \alpha, 6 \beta$ trihydroxycholanic acid will be an excellent marker for neonatal screening, and $\mathrm{N}-(3 \beta, 5 \alpha, 6 \beta$-trihydroxycholan-24oyl) glycine should be a good biomarker for the detection of children over 1 year of age affected with NPC. One limitation for these bile acids is that false positive results may occur in the case of patients with NPA and NPB, as well as with Wolman disease.

\section{Molecular analyses}

Results of biochemical biomarkers testing alone provide a very high suspicion of NPC which in several cases must be confirmed by genetic testing. Knowledge of the molecular 
background of NPC is also a significant part of the genetic counseling for the affected families and can potentially serve in the prenatal diagnosing.

The most commonly used diagnostic molecular method for NPC is Sanger sequencing, which uses the polymerase chain reaction (PCR). The NPCl gene is located on the 18q11.2 chromosome and consists of 25 exons. Till now, 390 pathogenic mutations have been found within this gene, including 265 missense / nonsense, 28 splicing, 54 small deletions, 31 small insertions, 2 small indels, 9 large deletions and 1 large insertion / duplication. The NPC2 gene located on the $14 \mathrm{q} 24.3$ chromosome consists of 5 exons. Till now, 23 mutations within this gene have been described, 17 missense / nonsense, 3 splicing and 3 small deletions (http://www.hgmd.cf.ac.uk/ 18. $01.2019)$. In $95 \%$ of NPC cases, pathogenic mutations are located in the NPC1 gene, and only 5\% in the NPC2 gene (Patterson et al. 2012; Vanier et al. 2016). Recently, PoleseBonatto et al. defined frequent mutations in $\mathrm{NPCl}$ gene and revealed 5 novel mutations in Brazilian NPC patients (PoleseBonatto et al. 2019). The most frequent mutation in this cohort was p.Ala1035Val (27.0\%), followed by p.Pro1007Ala (16. 9\%), and p.Phe1221Serfs*20 (14.6\%). Novel NPC1 variants were: one small deletion (p.Lys38_Tyr40del), one frameshift (p.Asn195Lysfs*2), and 3 missense mutations (p.Cys238Arg, p.Ser365Pro, and p.Val694Met).

The rare causes of NPC disease may also be deletions of exons or whole genes detected by MLPA (multiplex ligationdependent probe amplification) as well as mutations in the promoter region of the gene and deeply intronic. These changes can only be detected by next-generation sequencing (NGS)) (Vanier et al. 2016).

All biochemical and molecular techniques described in this review are summarized in Table 2 .

\section{Conclusions}

This review summarizes currently used diagnostic methods in recognizing NPC disease. Oxysterols, lysosphingomyelin isoforms and bile acid metabolites appear to be rapid, lowinvasive and inexpensive methods for initial screening, although they display certain limitations. These biochemical biomarkers may be increased also in other lysosomal diseases leading to false positive diagnoses. And on the contrary, results within the reference range do not necessarily exclude NPC. Biochemical biomarkers do not deliver a definite diagnosis and must be confirmed by molecular analyses such as Sanger sequencing or NGS. If a mutation of unknown pathogenicity is detected, the filipin staining test must also be performed in cultured skin fibroblasts.

Acknowledgements This work was supported by Narodowe Centrum Nauki (https://www.ncn.gov.pl) grant no. 2012/07/B/NZ1/02615.

\section{Compliance with ethical standards}

Conflict of interest The authors declare that they have no conflict of interest.

Open Access This article is distributed under the terms of the Creative Commons Attribution 4.0 International License (http:// creativecommons.org/licenses/by/4.0/), which permits unrestricted use, distribution, and reproduction in any medium, provided you give appropriate credit to the original author(s) and the source, provide a link to the Creative Commons license, and indicate if changes were made.

\section{References}

Alvelius G, Hjalmarson O, Griffiths WJ, Bjorkhem I, Sjovall J (2001) Identification of unusual 7- oxygenated bile acid sulfates in a patient with Niemann- pick disease, type C. J Lipid Res 42:1571-1577

Amraoui Y, Mengel E, Hennermann JB (2014) Oxysterols in NP type C: limitations of sensitivity and specificity. J Inherit Metab Dis 37(Suppl. 1):S150

Bauer P, Knoblich R, Bauer C, Finckh U, Hufen A, Kropp J, Braun S, Kustermann-Kuhn B (2002) NPC1: complete genomic sequence, mutation analysis, and characterization of haplotypes. Hum Mutat 19:30-38

Boenzi S, Deodato F, Taurisano R, Carrozzo R, Piemonte F, Bertini E, Pastore A, Dionisi-Vici C (2014) Evaluation of plasma cholestane$3 \beta-5 \alpha-6 \beta$-triol and 7-ketocholesterol in patients with NiemannPick type $\mathrm{C}$ disease and with other cholesterol metabolism related disorders. J Inherit Metab Dis 37:S144

Bremova T, Malinová V, Amraoui Y, Mengel E, Reinke J, Kolníková M, Strupp M (2015) Acetyl-dl-leucine in Niemann-Pick type C: a case series. Neurology 85(16):1368-1375

Bustamante A, Dominguez C, Rodriguez-Sureda V, Vilches A, Penalba A, Giralt D, Garcia-Berrocoso T, Llombart V, Flores A, Rubiera M, Molina C, Alvarez-Sabin J, Montaner J (2014) Prognostic value of plasma chitotriosidase activity in acute stroke patients. Int J Stroke 9:910-916

Chuang WL, Pacheco J, Cooper S, McGovern MM, Cox GF, Keutzer J et al (2014) Lysosphingomyelin is elevated in dried blood spots of Niemann-Pick B patients. Mol Genet Metab 111:209-211

Elmonem MA, Amin HS, El-Essawy RA, Mehaney DA, Nabil M, Kamel LN, Farid IM (2016) Association of chitotriosidase enzyme activity and genotype with the risk of nephropathy in type 2 diabetes. Clin Biochem 49:444-448

Erickson RP (2013) Current controversies in Niemann-pick C1 disease: steroids or gangliosides; neurons or neurons and glia. J Appl Genet 54:215-224

Ferraz MJ, Marques AR, Gaspar P, Mirzaian M, van Roomen C, Ottenhoff R et al (2016) Lysoglycosphingolipid abnormalities in different murine models of lysosomal storage disorders. Mol Genet Metab 117:186-193

Geberhiwot T, Moro A, Dardis A, Ramaswami U, Sirrs S, Marfa MP et al (2018) Consensus clinical management guidelines for NiemannPick disease type C. Orphanet J Rare Dis 13(1):50

Giese AK, Mascher H, Grittner U, Eichler S, Kramp G, Lukas J et al (2015) A novel, highly sensitive and specific biomarker for Niemann-Pick type C1 disease. Orphanet J Rare Dis 10:78

Hammerschmidt TG, de Oliveira Schmitt Ribas G, Saraiva-Pereira ML, Bonatto MP, Kessler RG, Souza FTS et al (2018) Molecular and biochemical biomarkers for diagnosis and therapy monitorization of Niemann-Pick type C patients. Int J Dev Neurosci 66:18-23 
Helmschrodt C, Becker S, Thiery J, Ceglarek U (2014) Preanalytical standardization for reactive oxygen species derived oxysterol analysis in human plasma by liquid chromatography-tandem mass spectrometry. Biochem Biophys Res Commun 446:726-730

Hollak CE, van Weely S, van Oers MH, Aerts JMJ (1994) Marked elevation of plasma chitotriosidase activity. A novel hallmark of Gaucher disease. Clin Invest 93(3): 1288-1292

Jiang X, Sidhu R, Porter FD, Yanjanin NM, Speak AO, te Vruchte DT, Platt FM, Fujiwara H, Scherrer DE, Zhang J, Dietzen DJ, Schaffer JE, Ory DS (2011) A sensitive and specific LC-MS/MS method for rapid diagnosis of Niemann-Pick $\mathrm{C} 1$ disease from human plasma. $\mathrm{J}$ Lipid Res 52:1435-1445

Jiang X, Sidhu R, Mydock L, Hsu FF, Covey DF, Scherrer DE et al (2016) Development of a bile acid-based newborn screen for Niemann- pick C disease. Sci Transl Med 8(337):337ra63

Jiang X, Sidhu R, Orsini JJ, Farhat NY, Porter FD, Berry-Kravis E, Schaffer JE, Ory DS (2019) Diagnosis of Niemann-Pick C1 by measurement of bile acid biomarkers in archived newborn dried blood spots. Mol Genet Metab 126(2):183-187

Kawazoe T, Yamamoto T, Narita A, Ohno K, Adachi K, Nanba E, Noguchi A, Takahashi T, Maekawa M, Eto Y, Ogawa M, Murata M, Takahashi Y (2018) Phenotypic variability of Niemann-Pick disease type $\mathrm{C}$ including a case with clinically pure schizophrenia: a case report. BMC Neurol 18:117

Klinke G, Rohrbach M, Giugliani R, Burda P, Baumgartner MR, Tran C, Gautschi M, Mathis D, Hersberger M (2015) LC-MS/MS based assay and reference intervals in children and adolescents for oxysterols elevated in Niemann-Pick diseases. Clin Biochem 48: 596-602

Ko DC, Binkley J, Sidow A, Scott MP (2003) The integrity of a cholesterol-binding pocket in Niemann-Pick $\mathrm{C} 2$ protein is necessary to control lysosome cholesterol levels. Proc Natl Acad Sci U S A 100:2518-2525

Kolter T, Sandhoff K (2006) Sphingolipid metabolism diseases. Biochim Biophys Acta 1758:2057-2079

Kuchar L, Sikora J, Gulinello ME, Poupetova H, Lugowska A, Malinova $\mathrm{V}$ et al (2017) Quantitation of plasmatic lysosphingomyelin and lysosphingomyelin-509 for differential screening of Niemann-Pick $\mathrm{A} / \mathrm{B}$ and $\mathrm{C}$ diseases. Anal Biochem 17:30094-30099

Lin N, Zhang H, Qiu W, Ye J, Han L, Wang Y, Gu X (2014) Determination of 7- ketocholesterol in plasma by liquid chromatography mass spectrometry for rapid diagnosis of acid sphingomyelinase deficient Niemann-Pick disease. J Lipid Res 55: 338-343

Liu N, Tengstrand EA, Chourb L, Hsieh FY (2014) Di-22:6bis(monoacylglycerol)phosphate: a clinical biomarker of druginduced phospholipidosis for drug development and safety assessment. Toxicol Appl Pharmacol 279:467-476

Maekawa M, Misawa Y, Sotoura A, Yamaguchi H, Togawa M, Ohno K, Nittono H, Kakiyama G, Iida T, Hofmann AF, Goto J, Shimada M, Mano N (2013) LC/ ESI-MS/MS analysis of urinary 3betasulfooxy-7beta-N-acetylglucosaminyl-5- cholen-24-oic acid and its amides: new biomarkers for the detection of Niemann- pick type $\mathrm{C}$ disease. Steroids 78:967-972

Malagarie-Cazenave S, Andrieu-Abadie N, Segui B, Gouaze V, Tardy C, Cuvillier $\mathrm{O}$ et al (2002) Sphingolipid signalling: molecular basis and role in TNF-alpha-induced cell death. Expert Rev Mol Med 20:1-15

Ory DS, Ottinger EA, Farhat NY, King KA, Jiang X, Weissfeld L et al (2017) Intrathecal 2-hydroxypropyl- $\beta$-cyclodextrin decreases neurological disease progression in Niemann-Pick disease, type C1: a non-randomised, open-label, phase 1-2 trial. Lancet. 390(10104): $1758-1768$

Pagan C, Latour P, Ruet S, Anselmini L, Piraud M, Pettazoni M, Cheillan D, Vanier MT, Vianey-Saban C (2015) Contribution of plasmatic biomarkers to the diagnosis of Niemann-pick type $\mathrm{C}$ disease. $\mathrm{J}$ Inherit Metab Dis 38:S57
Pajares S, Arias A, Garcia-Villoria J, Macias-Vidal J, Ros E, de las Heras J, Giros M, Coll MJ, Ribes A (2015) Cholestane- $3 \beta, 5 \alpha, 6 \beta$-triol: high levels in Niemann-pick type $C$, cerebrotendinous xanthomatosis, and lysosomal acid lipase deficiency. J Lipid Res 56:1926-1935

Patterson MC, Vanier MT, Suzuki K, Morris JA, Carstea E, Neufeld EB, Blanchette-Mackie JE, Pentchev PG (2001) Niemann-pick disease type C: a lipid trafficking disorder. In: Scriver ALBCR, Sly WS, Valle D, Childs B, Vogelstein B (eds) The metabolic and molecular bases of inherited disease. McGraw-Hill, New York, pp 3611-3633

Patterson MC, Vecchio D, Prady H, Abel L, Wraith JE (2007) Miglustat for treatment of Niemann- pick $\mathrm{C}$ disease: a randomised controlled study. Lancet Neurol 6:765-772

Patterson MC, Hendriksz CJ, Walterfang M, Sedel F, Vanier MT, Wijburg F (2012) Recommendations for the diagnosis and management of Niemann-pick disease type C: an update. Mol Genet Metab 106: 330-344

Patterson MC, Clayton P, Gissen P, Anheim M, Bauer P, Bonnot O, Dardis A, Dionisi-Vici C, Klünemann HH, Latour P, Lourenço CM, Ory DD, Parker A, Pocoví M, Strupp M, Vanier MT, Walterfang M, Marquardt T (2017) Recommendations for the detection and diagnosis of Niemann-pick disease type C. Neurol Clin Pract 7:499-511

Pentchev PG, Comly ME, Kruth HS, Vanier MT, Wenger DA, Patel S, Brady RO (1985) A defect in cholesterol esterification in Niemann-pick disease (type C) patients. Proc Natl Acad Sci U S A 82:8247-8251

Pettazzoni M, Froissart R, Pagan C, Vanier MT, Ruet S, Latour P et al (2017) LC-MS/MS multiplex analysis of lysosphingolipids in plasma and amniotic fluid: a novel tool for the screening of sphingolipidoses and Niemann-pick type C disease. PLoS ONE 12(7):e0181700

Polese-Bonatto M, Bock H, Farias ACS, Mergener R, Matte MC, Gil MS et al (2019) Niemann-pick disease type C: mutation spectrum and novel sequence variations in the human NPC1 gene. Mol Neurobiol Epub ahead of print

Polo G, Burlina AP, Kolamunnage TB, Zampieri M, Dionisi-Vici C, Strisciuglio P et al (2016) Diagnosis of sphingolipidoses: a new simultaneous measurement of lysosphingolipids by LC-MS/MS. Clin Chem Lab Med 17

Porter FD, Scherrer DE, Lanier MH, Langmade SJ, Molugu V, Gale SE, Olzeski D, Sidhu R, Dietzen DJ, Fu R, Wassif CA, Yanjanin NM, Marso SP, House J, Vite C, Schaffer JE, Ory DS (2010) Cholesterol oxidation products are sensitive and specific blood-based biomarkers for Niemann-pick $\mathrm{C} 1$ disease. Sci Transl Med 2:56-81

Raymond KM, Turgeon C, Ory D, Lourenço C, Giugliani R, Rinaldo P et al (2015) Combined analysis of plasma oxysterol and lysosphingomyelin,for Niemann-pick types A, B and C diagnosis. J Inherit Metab Dis 38(Suppl. 1):S36

Reunert J, Fobker M, Kannenberg F, Du Chesne I, Plate M, Wellhausen J, Rust S, Marquardt T (2016) Rapid diagnosis of 83 patients with Niemann pick type $\mathrm{C}$ disease and related cholesterol transport disorders by cholestantriol screening. EBioMedicine 4:170-175

Ribas GS, Souza HM, de Mari J, Deon M, Mescka C, Saraiva-Pereira ML, Kessler R, Trapp F, Michelin K, Burin M, Vargas CR, Giugliani R (2016) Selective screening of Niemann-pick type C Brazilian patients by cholestane- $3 \beta, 5 \alpha, 6 \beta$-triol and chitotriosidase measurements followed by filipin staining and NPC1/NPC2 gene analysis. Clin Chim Acta 459:57-62

Ries M, Schaefer E, Luhrs T, Mani L, Kuhn J, Vanier MT, Krummenauer F, Gal A, Beck M, Mengel E (2006) Critical assessment of chitotriosidase analysis in the rational laboratory diagnosis of children with Gaucher disease and Niemann-pick disease type a/B and C. J Inherit Metab Dis 29:647-652

Romanello M, Zampieri S, Bortolotti N, Deroma L, Sechi A, Fiumara A, Parini R, Borroni B, Brancati F, Bruni A, Russo CV, Bordugo A, Bembi B, Dardis A (2016) Comprehensive evaluation of plasma 7- 
ketocholesterol and cholestan-3beta,5alpha,6beta-triol in an Italian cohort of patients affected by Niemann-pick disease due to NPC1 and SMPD1 mutations. Clin Chim Acta 455:39-45

Sevin M, Lesca G, Baumann N, Millat G, Lyon-Caen O, Vanier MT, Sedel F (2007) The adult form of Niemann-pick disease type C. Brain 130:120-133

Solomon D, Winkelman AC, Zee DS, Gray L, Buttner-Ennever J (2005) Niemann-pick type $\mathrm{C}$ disease in two affected sisters: ocular motor recordings and brain-stem neuropathology. Ann N Y Acad Sci 1039: 436-445

Sotgiu S, Barone R, Zanda B, Arru G, Fois ML, Arru A, Rosati G, Marchetti B, Musumeci S (2005) Chitotriosidase in patients with acute ischemic stroke. Eur Neurol 54:149-153

Spiegel R, Raas-Rothschild A, Reish O, Regev M, Meiner V, Bargal R, Sury V, Meir K, Nadjari M, Hermann G, Iancu TC, Shalev SA, Zeigler M (2009) The clinical spectrum of fetal Niemann-pick type C. Am J Med Genet A 149A:446-450

Stampfer M, Theiss S, Amraoui Y, Jiang X, Keller S, Ory DS, Mengel E, Fischer C, Runz H (2013) Niemann-pick disease type C clinical database: cognitive and coordination deficits are early disease indicators. Orphanet J Rare Dis 8:35

Vanier MT (2010) Niemann-pick disease type C. Orphanet J Rare Dis 5:16

Vanier MT, Millat G (2003) Niemann-pick disease type C. Clin Genet 64: 269-281

Vanier MT, Rodriguez-Lafrasse C, Rousson R, Gazzah N, Juge MC, Pentchev PG, Revol A, Louisot P (1991) Type C Niemann-pick disease: spectrum of phenotypic variation in disruption of intracellular LDL-derived cholesterol processing. Biochim Biophys Acta 1096(4):328-337

Vanier MT, Gissen P, Bauer P, Coll MJ, Burlina A, Hendriksz CJ et al (2016) Diagnostic tests for Niemann- pick disease type C (NP-C): a critical review. Mol Genet Metab 118:244-254
Wajner A, Michelin K, Burin MG, Pires RF, Pereira ML, Giugliani R et al (2007) Comparison between the biochemical properties of plasma chitotriosidase from normal individuals and from patients with Gaucher disease, GM1-gangliosidosis, Krabbe disease and heterozygotes for Gaucher disease. Clin Biochem 40(5-6):365-369

Walterfang M, Yu-Chien C, Imrie J, Rushton D, Schubiger D, Patterson MC (2012) Dysphagia as a risk factor for mortality in Niemann-pick disease type C: systematic literature review and evidence from studies with miglustat. Orphanet J Rare Dis 7:76

Wassif CA, Cross JL, Iben J, Sanchez-Pulido L, Cougnoux A, Platt FM, Ory DS, Ponting CP, Bailey-Wilson JE, Biesecker LG, Porter FD (2016) High incidence of unrecognized visceral/neurological lateonset Niemann-pick disease, type $\mathrm{C} 1$, predicted by analysis of massively parallel sequencing data sets. Genet Med 18:41-48

Welford RW, Garzotti M, Lourenço CM, Mengel E, Marquardt T et al (2014) Plasma lysosphingomyelin demonstrates great potential as a diagnostic biomarker for Niemann-pick disease type $\mathrm{C}$ in a retrospective study. PLoS ONE 9:e114669

Wraith JE, Baumgartner MR, Bembi B, Covanis A, Levade T, Mengel E, Pineda M, Sedel F, Topcu M, Vanier MT, Widner H, Wijburg FA, Patterson MC (2009) Recommendations on the diagnosis and management of Niemann-pick disease type C. Mol Genet Metab 98: $152-165$

Zervas M, Somers KL, Thrall MA, Walkley SU (2001) Critical role for glycosphingolipids in Niemann- pick disease type C. Curr Biol 11: 1283-1287

Publisher's note Springer Nature remains neutral with regard to jurisdictional claims in published maps and institutional affiliations. 